\title{
Institutionalization of Nursing as Profession in the Early Twentieth Century Bengal
}

\author{
Sneha Sanyal* \\ (Received 05 March 2016; revised 14 February 2017)
}

\begin{abstract}
The article tries to identify the factors and the social forces which influenced the shaping of colonial policies about nursing and subsequent establishment of nursing training institutes and nursing organizations in the early twentieth century Bengal. Though nursing was recognized as an essential part of medical system - both in the European and Indian medical fraternity, the British Government was somehow reluctant to extend full support, both in terms of finance and institutional facilities. Even in the third or fourth decade of the twentieth century, modern nursing was restricted to the European and to some extent Eurasian women. Very few participated from the high caste Hindu families. The contemporary vernacular publication off course emphasized to train Bengali women in this new profession of nursing to upgrade the healthcare system with many a lacunas. However, the local belief (s) and communities helped to re-shape colonial policies of nursing - caste and gender practices of a traditional society.
\end{abstract}

Key words: Bengal, Colonialism, Hospitals, Nursing, Public health.

\section{INTRODUCTION}

The entry of European and Indian nurses was not uncommon at the time of illness and child birth in the 'inner-world' (antahpur) of the erudite Bengali families in the beginning of the twentieth century. In this context, Prasantakumar Pal, the biographer of Rabindranath Tagore, mentioned about a trained nurse, Golap Mohini Sarkar, who looked-after bed-ridden Mrinalini Debi (wife of the great Nobel laureate) in 1902 (Pal, 1990, pp. 95-96). But the situation was entirely different in ordinary Indians families including most of the elites. Scarcity of the trained nurses was one of the major hindrances of the Indian medical planning of the time. One Dr. Taraknath Das wrote to the editor of the Bangalakshmi, a leading journal of twentieth century Bengal, that our country needed thousands of Indian girls to be trained as nurses. He also wrote in his letter that recently fourteen girls graduated from an American Nursing Institute and among them one could find representatives from countries like Sweden, Switzerland, Norway, Russia, etc. ${ }^{1}$ At this the editor of Bangalakshmi requested the readers to think about the shortage of trained nurses in our country (1935). If the situation in the third decade of the twentieth century was so pitiable in terms of nursing, one can easily assume the condition at the beginning of that century! What was the status of the profession of nursing in the Indian society? What were the steps taken by the British Government to institutionalize the nursing profession? Can one find any initiative on the part of the 'natives', like scientific or technical education, to popularize the nursing profession?

Roy Macleod once observed that the success of Western medicine was facilitated by the expansion of hospitals to the non-European

\footnotetext{
*PhD Scholar, Department of History, University of Calcutta, West Bengal, E-mail: snehasanyal.2008@gmail.com

1 Bangalakshmi, Vol. 3, No. 10, Bhadra 1335 B.S. (1935), p. 771. Dr. Taraknath Das mentioned in his letter that he came to know about the incident from the New York Herald, published from Paris.
} 
world (Macleod, 1988, p. 3). Later on Jayanta Bhattacharya identified the treatment of the patient in a hospital setting (not in his/her domestic setting), in the Indian context, mainly signaled the beginning of the Western medicine in the midnineteenth century (Bhattacharya, 2014, pp. 231264). ${ }^{2}$ The hospital has become the main focus for the dissemination of Western medicine and plays a significant role in health care systems; not only on account of their curative functions, but also as centre of teaching and research. However, most of the literature concentrates on the medical, cultural and socio-political aspects of hospital developments in the colonial context (Harrison et al, 2009). But the contribution of Western medicine to the health of indigenous populations - hospital the symbol of modern medicine per se-cannot be understood without considering the role of the nurses, both as professionals and as working women in colonial perspective. In India, nursing is synonymous with Florence Nightingale's pioneering work in this field. She considered nursing along with midwifery as natural aptitudes of women and showed some reservations about women being trained as doctors. She wanted to see that nursing as a profession should get a strong and respectable foothold in society and the issue should not get lost in the wider political question of women's place in the medical profession (Gourlay, 2003, pp. 226-227). With this aim, Nightingale helped Lady Dufferin, the Vicereine, in her project for the promotion of female health care and education in India. In the course of time, the Dufferin project (1885) facilitated to produce a substantial number of female doctors, nurses, and midwives. But these incidents occurred in the late nineteenth century and are well-documented in the literature (Hasan, 2011; Sehrawat, 2013). The introduction of modern nursing and employment of female nurses - the two significant contributions of Nightingale - subsequently shaped the course of this profession as well as formed public opinion in favour of nursing among the Indian literati to a considerable extent in the early twentieth century.

\section{Towards Better Institutional Facilities: Early Diffident Steps}

Although the professionalization of nursing in Britain and America was still unfinished at the Victorian era, organized nurses began to seek wider spheres of influence and action in ways that reflected the contemporary vogue for the 'spirit of internationalism'. The international turn in nursing could be seen in the presence of nurses at world fairs, congresses, and conventions from the 1890s onwards; in coverage of occupational news from home and abroad in nursing periodicals; in busy networking between national nursing organizations and the fostering of particularly close ties between nurse leaders from Britain and America; and most notably, in the founding, in 1899, of the International Council of Nurses (ICN), a body explicitly designed to make 'new' nursing a force of global scope and significance (Tomes and Boschma, 1999, pp. 1-38). ${ }^{3}$

The professionalization of nursing was not exclusive to the western world only; it got considerable attention in the officialdom of the British India also. Here also the target public, like the colonial health care system, was the European

\footnotetext{
2 He also identified three other changes- a conceptualization of the two-dimensional bodily image to the three-dimensional one; touching and measuring the patient's body with a stethoscope, thermometer and other modes of inspection; and a transition to a new type of modern identity, i.e., from the socially embedded individual to case-number in a hospital.

3 The ICN's guiding culture was best expressed in the words of its founder, the British Nursing leader, Ethel Bedford Fenwick. In proposing the formation of a worldwide confederation of nurses, Fenwick insisted that 'a sisterhood of nursing is an international idea and one in which the women of all nations, therefore, could be asked and expected to join'. Barbara L. Brush and Meryn Stuart, 1994, p. 195.
} 
domiciled in India. To provide 'best' treatment along with well-trained doctors and good hospitals, nurses were considered an indispensible part of the medical health-care system. Thus a scheme was originated as early as 1905 in spite of the political disturbance caused by the partition of Bengal.

It was called 'Scheme for the provision of trained nurse (s) for attendance on Europeans in India' and Her Excellency Lady Curzon was closely associated with it. The scheme was originally restricted to the European civil gazetted officers - health of the top-level bureaucracy was the prime concern of the Raj. But while discussing on the matter with other provincial heads, Government of India realized that the need for 'efficient nursing in dangerous sickness' for the non-official and official population was same. They could not differentiate these two classes on the basis of their designation. ${ }^{4}$ The scheme, the Government of India believed, had great potential as it intended to widen the range to include all the local governments and provinces under it and also to utilize the networks of the agencies already involved in providing European trained nurses in India. But at this stage it would be unwise to implement the scheme in a uniform manner-i.e. among the Indian population also. The Government of India cited the huge difference between the 'surroundings and manner of life' of the Europeans and their Indian counterpart as an obstacle to provide European nurses to the latter. Therefore it was desirable to confine the benefits of the scheme to the Europeans only.
This scheme is very significant from the point of view of institutionalization of nursing profession in India. It needs a thorough attention to understand the different layers involved in the whole process. It was the brain-child of Lady Curzon. She was interested to create a service of highly trained European nurses to look after the European population, both official and nonofficial, throughout the country. An Indian Nursing Service, administered by one central authority, was visualized and for smooth functioning of the organization the nurses would be allotted to various provinces. To make it attractive to the potential candidates, the scheme proposed to recruit nurses on a permanent basis with pension benefits. It also suggested that the nurses allotted to each province would be placed at the adjacent quarters (nurses' home) of a European hospital on the every possible occasion.

Erection of nurse's quarters attached to a hospital premises was a common practice in those days. Basically for the reason of convenience, both to the hospital authorities and nurses themselves, these structures were raised one after another in the nearby places of the hospitals. For a quick example - the proposal made by the InspectorGeneral of Civil Hospitals, Bengal, was approved to acquire 'the strip of land between the compound of the Eden Hospital and College Street' required as the site for the new nurses' quarters in connection with the Calcutta Medical College Hospital. ${ }^{5}$ It was also expected that the nurses in each province should spend at least one month of each year at a sanitarium in the hills. But it was

\footnotetext{
${ }_{4}$ Government of Bengal, Municipal Department, Medical Branch, File No. N/3, Progs. No. 12-17, April 1905, West Bengal State Archives, Kolkata (hereafter WBSA).

5 Government of Bengal, Municipal Department, Medical Branch, File No. 2M/5, Progs. No. 30, November 1904, WBSA. The advantages of this system was twofold- "(1) The nurses will be under the general supervision of the matron or superintendent of the hospital, who will see to their accommodation and interests when they are not engaged upon nursing duty, and will also attend to and arrange to meet requisitions for their services, receiving in return a reasonable allowance from the Association's funds; (2) They will, when unemployed in private nursing, be utilized in nursing cases in the hospital and will thus be kept in constant practice. The hospital also will not improbably be glad to avail itself of their services during such periods. But even if the advantages to the hospital of such intermittent assistance be slight, the benefit to the nurses of constant employment will be appreciable." Government of Bengal, Municipal Department, Medical Branch, File No. N/3, Progs. No. 12-17, April 1905, WBSA.
} 
not intended that the period of residence in the hills, with work assignment to various European hospitals, should be treated as leave.

The Government of India also advised the terms of appointment for nurses in this country-

\begin{abstract}
“(a) Candidates must have passed a full course of training at a London hospital or similar European institutions, and must be in possession of full certificates of efficiency and satisfactory evidence as to character and physique; (b) They will be provided with $2^{\text {nd }}$ Class passes to India and will enter into agreements to serve the association wherever ordered, for a period of five years, and it will be open to them to re-engage with the consent of the association for the two further periods of five years' service; (c) They will draw salary at the rate of Rs. 75 a month, for the first five years, and Rs. 100 during the second and third periods of service; (d) In addition to salary they will be provided by the association with free quarters, and an allowance to cover the cost of uniform, lights, attendance and fuel; (e) After five years service it will be open to them to retire on a gratuity of Rs. 500 , after 10 years' service on a pension of $£ 25$ and after 15 years' service on a pension of $£ 40$." 6
\end{abstract}

Thus the Indian Government tried to make this service lucrative to the trained European nurses. European residents were invited to contribute to the funds at the rate of Rs. 1 a month. For the government officials the amount could be simply deducted from their salary and the nonofficials it would be necessary to provide an agency of collection. The subscribers, including their families, of this scheme had a preferential claim on the assistance of the nurses in case of sickness and could obtain their services at a favourable rate of Rs. 5 per day as compared to Rs. 6 a day charged to non-subscribers.
Lady Curzon in a letter to the Government of India written in early 1904 identified the diseases - enteric fever and dysentery — which proved most fatal to the European population in India and accordingly needed skillful nursing and carefully prepared diet. She also elaborated the need for trained European nurses in large numbers especially in the suburbs and small localities and thus compelled one to take the help of the ignorant native servants. ${ }^{7}$ The Government were also aware of the situation as in Bengal most of the nurses in spite of their nursing skills were native Indian or with a mixed origin. Thus the need for more European nurses gradually increased in the official circle and with this increase the need of properly equipped hostels for them among the residents in Calcutta who had hitherto been able to obtain the assistance of country-trained nurses. The Government desired to place the imported European nurses for Bengal under the management of a sub-committee of the Calcutta Nurses' Institution. Then all nursing of private patients in their own homes was performed by a staff of eight nurses resident in the Lady canning Home. The trained European nurses would eventually substitute them. It was decided that Calcutta would provide the required number of nurses. An agency in England to select and dispatch trained nurses to India was also urgently felt. The provincial committee would consist of the principal civil medical officer of the province, the wife of the Lieutenant-Governor of the province or other head of the civil administration and of the secretary of the local government who involved in medical administration of the province. The function of this committee was confined to supervising the discipline and employment of the nurses. ${ }^{8}$

By the first decade of twentieth century itself the scarcity of nursing personnel was a

\footnotetext{
${ }^{6}$ Government of Bengal, Municipal Department, Medical Branch, File No. N/3, Progs. No. 12-17, Ibid.

7 Letter of the Secretary, Lady Curzon's Committee to the Secretary to the Government of India, Home Department, Dated: January 29, 1904; Ibid.

8 Ibid.
} 
serious concern for not only the government officials, but for the medical professionals also. This is evident from a letter written by LieutenantColonel C P Lukis, Principal of the Calcutta Medical College to the Secretary, Calcutta Hospital Nurses' Institution (1906). He began his letter in a cautionary tone, "It has long been recognized that the nursing staff of Medical College Hospital is insufficient to meet the requirements of that institution...no serious steps have hitherto been taken to remedy this defect." 9 The condition of the Medical College Hospital, the premier hospital of Calcutta, was really striking in terms of nursing. There was only one nurse available for the charge of 'each group of four wards' (at least 64 beds) throughout day and night! Even there was no supervision available of nightnurses. Again for the Ezra Hospital, Lukis narrated, there was only one nurse entirely responsible for everything. As a result during the night hours the patients remained absolutely unattended. Lukis also raised the monetary issue related to the nursing service which was considerably low. Government was spending large sums of money to improve the infrastructure of the hospitals, but all these would be of little use unless providing efficient nursing for the sick. ${ }^{10}$

In the very next year of Lukis's letter (1906), the Bengal Government took 3 steps to strengthen the nursing profession in the province. They increased the number of nurses, recruited 15 additional nurses only for the Calcutta Medical
College Hospital, and raised the payment to the Hospital Nurses' Institution from the Hospital Port Dues Fund by about Rs. 9000 per year. ${ }^{11}$ Thus from the official accounts so far we discussed, one can easily understand the shortage of efficient nurses hampered the entire healthcare system of Bengal.

This shortage of skilled nurses worsened the situation during the time of outbreak of an epidemic. The government had very limited options then-one was to recruit trained nurses on a temporary basis. In one such case at the request of the Inspector-General of Civil Hospitals, the Bengal Government sanctioned the temporary employment of nurses up to maximum number of six at the Campbell Hospital to tackle the menace of small-pox. ${ }^{12}$ There was a growing call for trained nurses from colonial doctors also practicing in various places of India. Writing from Delhi in 1910, Jenny Muller, a missionary doctor with considerable experience in this country, reported: "It is no exaggeration to say that in India today the call for nurses is much louder than that for women doctors." ${ }^{13}$ In India, colonial doctors were becoming increasingly conscious of their need for nurses, in large part due to the rising number of hospitals and the growing acceptability of in-patient treatment among the local population. Thus in April 1906 eight additional nurses were recruited in the Campbell Hospital 'on a pay of Rs. 30 per mensem and a diet allowance of Rs. 8 a month each'. ${ }^{14}$ In the practice of modern medicine, trained nurses had come to be seen as

\footnotetext{
9 Letter dated the $25^{\text {th }}$ February, 1906. Government of Bengal, Municipal Department, Medical Branch, File No. G/1, Progs. No. A-1-5, July 1906, WBSA.

${ }^{10}$ The disheartened Principal wrote- "I may ask to picture to themselves what is happening every night in the Medical College and Ezra Hospital: in the former institution, a solitary nurse, without any supervision or assistance, is struggling through the long hours of darkness to minister to the needs of 64 patients, scattered over four large wards; whilst in the latter there is no attempt at night-nursing at all. When we remember how the vitality of the sick ebbs towards the early hours of the morning, and what a large proportion of them pass away with the dawn, it must be admitted that our patients do not receive the attention they require in their hours of greatest needs and that the increase in the nursing staff is absolutely and urgently necessary." Ibid.

${ }^{11}$ Government of Bengal, Municipal Department, Medical Branch, File No. N/3, Progs. No. 57-60, May 1907, WBSA.

${ }^{12}$ The temporary nurses would receive pay at the rate of Rs. 50 a month and a dietary allowance of Rs. 8. Government of Bengal, Municipal Department, Medical Branch, File No. 2C/4, Progs. No. 69-70, February 1907, WBSA.

${ }^{13}$ Jenny C. Muller, Some Personal Reminiscences of Work in the Delhi Medical Mission 1884-1910, Delhi: Cambridge Mission to Delhi, 1910, p. 12; quoted in Fitzgerald, 2006, p. 204.

${ }^{14}$ Government of Bengal, Municipal Department, Medical Branch, File No. 2C/9, Progs. No. B—9-11, April 1906, WBSA.
} 
essential to the routine running of these institutions and were now regarded as natural 'corollaries' of the modern hospital.

But in spite of such growing demand for better nursing facilities in the hospitals, the colonial government acted strangely. As we have seen Lady Curzon had attempted to establish an ambitious system of private nursing (essentially for Europeans) that demanded significant state funding. Her plans were rejected by the India Office on grounds of excessive expense. In the year 1907 the scheme which had been originally formulated by Lady Curzon for the provision of trained nurses to attend the domiciled Europeans in India was suddenly revoked. The Government of India intimated the Bengal Government that its place (Lady Curzon's scheme) was taken by a scheme drawn up by Lady Minto - called Indian Nursing Association after her name. ${ }^{15}$ By the early twentieth century, Rosemary Fitzgerald argues, many European medical women working in India were in sympathy with the growing demand for professional nurses (Fitzgerald, 2006, p. 205). The call for nurses to serve in India did attract considerable fanfare. Some sought a career in India as private nurses, either as independent practitioners or as employees of the new organizations that had sprung up to serve European community and Indian dignitaries 'living European-style'. The most notable of these was the Up-Country Nursing Association, established in 1892 , initially to provide private-duty nurses in the Punjab and the United Provinces, but later extended to cover other provinces. ${ }^{16}$ This organization was amalgamated with the newly established Lady Minto's Indian Nursing Association (1906). These and other smaller organizations serving the same purpose were independent of government although in receipt of state aid and assistance.

In 1909 the then Lieutenant-Governor of Bengal Sir Edward Norman Baker (1908-11) decided to include this province under the purview of the 'Lady's Minto's Indian Nursing Association'. Accordingly the Bengal Government established a provincial branch committee. The members were selected on the terms that they would hold their post for two years and be eligible for re-appointment after expiry of that timeframe. ${ }^{17}$ It was also decided after consultation with the Calcutta Hospital Nurses' Institution that the provincial branch committee would supply and recruit out-nurses for Calcutta and throughout the Province. The only condition which the Calcutta Hospital Nurses' Institution desired to include was that the association would reserve 'at least twofifths of the appointments of their staffs for qualified locally trained Hospital Nurses. ${ }^{18}$ The government happily agreed.

Around that time an important decision was taken. This was regarding the reorganization of the nursing arrangements at the Presidency General and Medical College Hospitals. The Bengal Government decided that at the above mentioned hospitals the sisters would take personal care of the nurses, exercise supervision on them in their quarters, and be responsible for

\footnotetext{
${ }^{15}$ Government of Bengal, Municipal Department, Medical Branch, File No. N/4, Progs. No. B-32, February 1907, WBSA.

${ }^{16}$ Home, Medical, July 1903, Nos. 208-209, National Archives of India, New Delhi (hereafter NAI).

Lady Minto's predecessor as Vicereine, Lady Curzon proposed a gigantic plan to institutionalize nursing profession. But her scheme remained unheeded after considerable discussion and debate. If implemented, her plan could have been exemplary in nature.

${ }^{17}$ The Provincial Branch Committee: Lady Baker (President); The Hon'ble Mr. F. A. Slacke, CSI; Colonel R. Macrae, IMS, Inspector General of Civil Hospitals; W. Muir, Esq.; W. T. Grice, Esq.; H. W. Sparkes, Esq.; Mrs. H. L. Stephen, Mrs. Archie Birkmyre, Captain C. J. Allansen (Honorary Secretary). Government of Bengal, Municipal Department, Medical Branch, File No. N/3, Progs. No. A—48-59, March 1909, WBSA.

Surprisingly the Committee was devoid of any Indian members!

18 Ibid.
} 
that portion of their training which relates generally to nursing, but their 'medical and surgical training must be given by the medical staff.' ${ }^{19}$ The Sister Superior would allot her subordinate sisters to the different wards and interchange them when necessary, in consultation with the medical officers in charge of the hospitals. The Bengal government and Calcutta Municipal Corporation agreed to increase their contributions in terms of nursing towards the support of the hospitals in Calcutta. ${ }^{20}$

\section{Modern Nursing and Indian Society}

When Western nurses came to India as emissaries of the profession, they brought with them an extensive cultural heritage. From the late nineteenth century better-trained and more skilled nurses began to arrive in India. These more competent nurses reflected the increasingly important role that nursing was playing as a dimension of Western medical modernity. According to Charles Rosenberg, the hospital 'assumed its modern shape' roughly between 1870 and 1920 (Rosenberg, 1987, p. 234). Medicine became increasingly technological in nature by then and the hospital was transformed from a refuge for the poor to a desirable site for treatment across the social classes. This brought about a new dependence on the nurses, who came to play an integral role in the more complex modes of treatment now required.

The new generation of Euro-American nurses entering India at the beginning of the twentieth century, Rosemary Fitzgerald argues, was secure in the knowledge that they represented the very cream of their profession. Those working in hospital settings saw their mission as twofoldto implement more efficient systems of ward management and to improve the chaotic state of training and supervision of local staff employed in these institutions (Fitzgerald, 2006, p. 206). Later commentators express somewhat symmetrical view. Madelaine Healey, for example, argues that the British Empire played a significant role as an arena in which this new importance and professional confidence could be played out. As the systematization of nursing increased and its importance became more generally accepted, the profession sought to express its newfound confidence more widely in the early twentieth century (Healey, 2013, pp. 28-9). There was a strong sense felt by some nurses of their role as the 'bearers of enlightened, progressive scientised models, both of care and of emancipated womanhood'. Western nurses felt committed, Healey continues, to the notion of reproducing in India their exciting new role in the modern institution of the hospital.

The reform of nursing profession was still an on-going project in the West in the late nineteenth century. The new breed of nurses, who came to India around this time, realized the importance of cooperative rather than individual action and the need for professional solidarity. Thus seven nursing superintendents working in the northern part of India met in Lucknow to form the Association of Nursing Superintendents of the United Provinces and the Punjab (1905). In the very next year, the Association broadened its agenda by changing the name to the Association of Nursing Superintendents of India (Gayathri, 2007, p. 161). ${ }^{21}$ Through their efforts, the Trained Nurses' Association of India (TNAI) was formed in 1908. The symbolic importance of the International Council of Nurses (ICN) for organized nursing in the early twentieth century

\footnotetext{
${ }^{19}$ Government of Bengal, Municipal Department, Medical Branch, File No. N/4, Progs. No. 42-44, March 1909, WBSA.

${ }^{20}$ Government of Bengal, Municipal Department, Medical Branch, File No. N/4, Progs. No. 63-69, August 1909, WBSA.

${ }^{21}$ The Association's primary objective was to elevate nursing education by obtaining a better class of candidates, by raising the standard of training and striving to bring about a more uniform system of education, examination and certification for trained nurses, both Indian and European.
} 
was clearly visible in the TNAI's stated ambition to be 'on a small scale what the International Council of Nurses is on a large scale' (Mill, 1910, p. 12). The Association of Nursing Superintendents and TNAI were organizationally inseparable and ideologically indistinguishable. Both bodies shared the same official goals which voiced mainly through their joint publication, the Nursing Journal of India (1910). In calling for trained nurses from all communities in India to join the TNAI, Miss Mills, Lady Superintendent of St. George's Hospital (Bombay) echoed the similar words of the ICN's founder and first President, Ethel Fenwick - 'there is no nationality in nursing'.22 But despite this inspiring announcement, opinion was considerably divided to raise the issue of forming a separate branch for Indian nurses at the annual conference of TNAI in 1910. Their members were overwhelmingly Anglo-American. From the contemporary accounts, one can find only one Indian nurse on the TNAI membership list for 1910-Rosie Singh, trained by missionaries in Ludhiana and worked at the Sarah Steward Mission Hospital (Allahabad) (Dock, 1912, p. 254).

In the above mentioned annual conference of TNAI (1910) it was decided that Indian nurses should be admitted to TNAI in a large numbers on the same basis as others - all being required to have a three-year training at a reputable nursing school under the charge of a European superintendent. ${ }^{23}$ In 1912, when the TNAI became the first nursing association outside the West to gain affiliation with the International Council of Nurses (ICN), international nursing leaders applauded the fact that 'those forefront of Indian nursing affairs took the right and just position' in admitting Indian nurses into the national association (Dock, 1912, p. 256). Although there was no racial bar to membership, Indian nurses were rarely represented in the TNAI. This partly reflected the eligibility requirements - it was widely reported that no fully trained Indian nurses existed before 1905. But it is certainly true that at the time of the TNAI's formation and for some later years, many Indian probationers continued to pass through training programmes judged insufficient for TNAI membership (Bridges, 1967, p. 40). But even if they were eligible, many Indian nurses may have had no desire to join an organization so transparently Eurocentric in nature. Furthermore, TNAI excluded maternity nurses and midwives. The relatively brief training period for this type of nursing, as well as its focus on mothers and infants, made it more appealing than general nursing to Indian women. But the TNAI did not consider these aptitudes equal to a three-year nursing course. A separate organization for these lower categories of nurses was eventually established in the 1920s. Thus, Rosemary Fitzgerald identifies, reproduced the 'caste-like' intra-professional divisions of Western nursing (Fitzgerald, 2006, p. 208). Dias were excluded altogether, belonging to the indigenous medical tradition, they were not included in the functionaries associated with modern medicinenursing.

During 1920-30, there was a considerable development in nursing education. Training of nurses, midwives and health visitors became more standardized. Training schools was established in all the provinces and also in many of the Indian states. Various grades of training for nurses were established. For example, the course in general

\footnotetext{
${ }^{22}$ Ibid, p. 14. Fenwick, the Founder-President of ICN, was made an honorary member of the TNAI in 1914.

${ }^{23}$ Everybody was not happy with such arrangements and wanted to maintain the racial order of colonial society among the nursing ranks also. For example, Miss Bonser, the Association's Secretary and Treasurer, expressed the view that Indian nurses 'know themselves that they are not the equals of European nurses, and it would be a great shock and surprise to them to be put on an equality.' Proceedings of the Second Annual Conference of the TNAI, December 1910, Benares, quoted in The Nursing Journal of India, Vol. II, No. 2, February 1911, p. 5.
} 
nursing has been of three years duration since the early years of the twentieth century, but two standards were established in many of the places, including Bengal. These two standards were known as Senior or 'A' Grade and Junior or 'B' Grade. ${ }^{24}$ This grading applied both to men and women nurses. The basic difference between the two courses lay in educational standard of pupils and the medium of instruction. The ' $A$ ' Grade course was given in English while the 'B' Grade course was given in vernacular. There was similar grading for midwives, but in their case the duration of the course was raised from six months to one year for trained nurses and from 18 months to 2 years for others. The duration of the course was also raised from 12 months to 18 months for health visitors but a certificate in midwifery was a prerequisite in all cases. An exemption of three months from the training period was given to candidates who were qualified nurses. ${ }^{25}$ In the meanwhile the authorities of the Calcutta Medical College Hospital reduced the number of civil pupil nurses and increased the number of Indian pupil dias. ${ }^{26}$ This was altogether a general tendencythe number of civil pupil nurses was reduced from 20 to 14 and the number of Indian pupil dias was increased at the Eden Hospital also.

But the increased number of European and Anglo-Indian nurses in the colonial health-care system annoyed the Indian erudite. As the newly appointed Minister-in-Charge of the Department of Local Self-Government Bijoy Prosad Singha Roy asked two important questions regarding the policy of the Bengal Government in the Assembly- "...whether it is a fact that all the nurses in the Calcutta Medical College Hospital are either Europeans or Anglo-Indians? If so, are the Government considering the desirability of appointing Indians as nurses in the Medical College Hospital?" 27

At this Sir Surendra Nath Banerjee, the Hon'ble Minister in the Cabinet of the Bengal Government replied that the nurses of the above mentioned hospital were not all Europeans or Anglo-Indians. There were 21 nurses employed at the Eden Hospital with an Indian origin. But those were supplied and paid by the Calcutta Hospital Nurses' Institution were Europeans and Anglo-Indians. Regarding Bijoy Prasad's second question, Banrejee responded in negative. There was no proposal, at present, to appoint Indian nurses at various hospitals of the Province in large numbers. ${ }^{28}$

The government was trying to improve the infrastructure of the hospitals in terms of nursing no doubt. Works started with right earnest at the Lady Minto's Nursing Sisters' Quarters at Jalpaiguri and at the Nurses Home of Dacca Mitford Hospital. ${ }^{29}$ But one should keep in mind the colonial connection of the Bengal Government. So it was not spontaneous regarding funding to the health-care sector of the subject population. Their interest was somewhere else! Thus when the Secretary to the Lady Minto's Nursing Association requested to make provision for an additional grant for the Darjeeling Home, the Bengal Government turned down the request as

\footnotetext{
${ }^{24}$ Development of Nursing Education in India, 1966, p. 8.

${ }^{25}$ Ibid, p. 9.

${ }^{26}$ Government of Bengal, Local Self-Government Department, Medical Branch, File No. N-1, Progs. No. B 348-52, December 1921, WBSA.

${ }^{27}$ Government of Bengal, Local Self-Government Department, Medical Branch, File No. Q. 19, Progs. No. A. 11-16, January 1922, WBSA.

${ }^{28}$ But Surendranath assured his colleague in the Cabinet that "when the new block of quarters for nurses is ready and working, an extension of the employment of Indian nurses is contemplated." Government of Bengal, Local Self-Government Department, Medical Branch, File No. 1 H-1, Progs. No. B. 280-83, January 1922, WBSA.

${ }^{29}$ Government of Bengal, Local Self-Government Department, Medical Branch, File No. N-3, Progs. No. B. 222, January 1922, WBSA.
} 
they were not satisfied to the necessity of such additional grant. ${ }^{30}$ On another similar occasion the Government informed the Secretary to the Calcutta Hospital Nurses' Institution that owing to the strident financial crisis it had been found impossible to retain the assurance of additional grant to the organization. ${ }^{31}$

But there were several positive points also - a trained surgical nurse, of course European was appointed at the Campbell Hospital and this period also witnessed the entry of Indians in the Governing Body of the Calcutta Hospital Nurses' Institution. ${ }^{32} \mathrm{G} \mathrm{N}$ Banerjee, MA, and Dr. B C Ghosh were appointed as the members of the prestigious Calcutta Hospital Nurses' Institution. ${ }^{33}$ But unfortunately we do not have much information about them. In the year 1924 recognition came from the General Nursing Council for England and Wales of the nursing certificates granted by the State Medical Faculty, Bengal. ${ }^{34}$ This was undoubtedly a big achievement.

Throughout these periods employment of temporary nurses was rampant in various hospitals. This tendency is very much linked with the outbreak of various epidemics. For a quick example, in 1928, three temporary nurses were recruited at the Campbell Medical School and Hospital. The Government of Bengal decided to employ additional nurses on the same pay-diet allowance-house-rent when the number of patients at the cholera ward of the Campbell Hospital suddenly increased. ${ }^{35}$ Government tried to solve the resource crunch, i.e., to increase the number of trained nurses in Bengal. A proposal was made by the Surgeon-General of Bengal to allow travelling allowance (TA) to the pupil nurses of the Mitford Hospital, Dacca, for appearing at the State Medical Faculty Examinations held in Calcutta. The Bengal Government agreed in principle to grant TA at 'inter-class rates' for each journey to and from Calcutta for the students of Dacca Mitford Hospital. ${ }^{36}$ On another occasion, again the Surgeon-General recommended the Government to sanction 'grant of pay' and 'messing allowance' for two students of the Sambhu Nath Pandit Hospital of Bhawanipur who were unsuccessful at the State Medical Faculty Examination. Thus sanction was accorded for 2 pupil nurses of that institute to continue for a period of three months only of the pay and messing allowance at the rate of Rs. 20 and Rs. 12 per month respectively. ${ }^{37}$ These were all initiatives in the part of the Government to increase the number of nurses to assist in the health care system of the Province.

From the annual report (1926) on the working of hospitals and dispensaries under the Government of Bengal one can get the dismal state of nursing-

\footnotetext{
${ }^{30}$ Government of Bengal, Local Self-Government Department, Medical Branch, File No. N-4, Progs. No. B. 339-40, March 1921, WBSA.

${ }^{31}$ Government of Bengal, Local Self-Government Department, Medical Branch, File No. N-2, Progs. No. B. 438-41, May 1921, WBSA.

${ }^{32}$ Government of Bengal, Local Self-Government Department, Medical Branch, File No. 1C—8, Progs. No. B 7-15, August 1924, WBSA.

${ }^{33}$ Government of Bengal, Local Self-Government Department, Medical Branch, File No. N-2, Progs. No. 177-78, June 1924, WBSA.

${ }^{34}$ Government of Bengal, Local Self-Government Department, Medical Branch, File No. N-3, Progs. No. B. 236-45, May 1924, WBSA.

${ }^{35}$ Government of Bengal, Local Self-Government Department, Medical Branch, File No. 1C-16, Progs. No. B 43-49, September 1928, WBSA.

${ }^{36}$ Government of Bengal, Local Self-Government Department, Medical Branch, File No. 1H—38, Progs. No. B 60-61 (Permanent), March 1928, WBSA.

${ }^{37}$ They were unsuccessful in the last examination for nursing of the State Medical Faculty of Bengal. Government of Bengal, Local Self-Government Department, Medical Branch, File No. N-7, Progs. No. 68-70, March 1928, WBSA.
} 


\begin{tabular}{|lcc|}
\hline Name of the Hospitals & Number of Nurses & $\begin{array}{c}\text { Average Number of In-door } \\
\text { Patients Per Nurse }\end{array}$ \\
\hline Medical College Group of Hospitals & 183 & 3.19 \\
Presidency General Hospital & 80 & 2.51 \\
Carmichael Hospital for Tropical Diseases & 20 & 4.08 \\
Campbell Hospital & 52 & 25.99 \\
Carmichael Medical College Hospital, Belgachia & 44 & 5.40 \\
Lady Dufferin Victoria Hospital & 32 & 3.22 \\
Sambhu Nath Pandit Hospital & 25 & 3.88 \\
Sree Vishnudhananda Saraswati Marwari Hospital & 18 & 9.00 \\
\hline
\end{tabular}

This was the condition of nursing in and around of Calcutta, the principal city of the Province. The provision of the hospitals and dispensaries of the district towns and other remote places was obviously pathetic than Calcutta. The report itself stated: "In most mufassal institutions nursing duties are left to the relatives of patients, hospital dressers, compounders or ward coolies as before." 38

The Indian erudite was not a mere spectator in the early twentieth century. The dismal state of nursing did produce ripples both in the minds of the medical practitioners and learned Bengalis. Unlike the field of technical knowledge, where the unsatisfied Bengali intellectuals with the state-sponsored engineering curriculum came up with their own model (Sarkar, 2012, pp. 13644), here their response was not so radical. But aware about the significance of nursing in the healthcare system of a country, the Bengali intellectuals voiced their concern in the contemporary vernacular journals and periodicals. This was very important. The western technoscientific and medicinal knowledge, viewed as a cultural import, was actively redefined by the recipient culture. A close contact with a vibrant, though alien culture could not have failed to produce curiosity in the minds of the local people. A different society, culture, tradition and existing indigenous knowledge systems provided the context in which the gradual spread of this occurred, followed by its adaptation and articulation through various reformulations (Bose, 2006 , pp. 1-4). One of the primary means of reformulation and appropriation of such knowledge were the journals and periodicals written in Indian languages. Bengal was an ideal example - the response of the Bengali erudite to the modern nursing testifies their awareness of the new phenomenon of hospital system and this very much evident in the contemporary Bengali press of the twentieth century. For our discussion Bangalakshmi, a monthly periodical under the editorship of Hemlata Debi, is very relevant in terms of nursing. ${ }^{39}$ This periodical reported about an indigenous initiative in the field of nursing in 1929-

"Under the supervision of Dr. Hemendra
Narayan Roy, the Sarojnolini Nursing
School is functioning well with the
assistance of Dr. K K Dhar, Dr. S N
Chatterjee and Dr. M Saha. Lectures on
anatomy, surgical home nursing,
midwifery, first-aid and bandaging and
physiology are already over. For practical

\footnotetext{
${ }^{38}$ Government of Bengal, Local Self-Government Department, Medical Branch, File No. 1R-2 (1), Progs. No. 5-6, February 1927, WBSA.

${ }^{39}$ This periodical began publishing from 1924 (1331 B.S.) and continued for a considerably long period. Issues related to women and family appeared on the pages of this periodical. Biographies of contemporary women of repute also came along with fiction literature and essays on religions and moral issues.
} 
training, the student nurses of this school are sent regularly at various hospitals. The credit for this initiative entirely goes to Dr. Hemendra Narayan Roy who tirelessly has been working for the upgrade of this school." $" 40$

In the previous issue, the periodical published an advertisement of the Sarojnolini Nursing School. From there one can get the following information- "For the training in nursing, we need respectable women from the high caste Hindu families. It is desirable that the upper age limit of such women is 18 years and educational qualification should be $4^{\text {th }}$ Standard of an English school. The applicants have to furnish documentary proof. Provision for scholarships is also there-something between Rs. 15 to 20. The nearby nurses' quarters of a hospital are currently used to accommodate pupil nurses. All applications should be addressed to the lady Secretary of the Sarojnolini Nursing School. They have to produce character certificate from a women organization or a reputed government employee." ${ }^{41}$ In the year 1931 the Health Department of the Calcutta Municipal Corporation organized an exhibition in the ward number 20 under its jurisdiction. The students of the Sarojnolini Nursing School participated in the event in large numbers and their performance was noticed with admiration by the respectable citizens. ${ }^{42}$

In one article appeared in the same periodical, Bina Dutta emphasized the valiant role of Nightingale in the Crimean War and her contribution in popularizing the modern nursing. The phrase 'Heroic Womanhood' rightly suits Nightingale. Dutta continued with the close proximity between nursing, a noble profession, and the character of Bengali women. Basically the correct translation of 'Seba', a Bengali word, in English is nursing. It goes well with the soft and kind nature of the Bengali women. ${ }^{43}$ Another characteristic of this period was the reflection of the nursing profession in the friction literature. In most of the cases the profession was represented as a medium to empower the women especially the helpless and poor. But most of them, as the literature portrayed, belonged to the low caste Hindus or Christians - nursing was not a descent profession for the high caste Hindu women. ${ }^{44}$

One Prallahad Chandra Chakroborti, while admiring the Mohila Samiti (Women Organizations), elaborated how some of these organizations involved in the teaching of nursing. In one such case, Dr. S C Das with a foreign-degree helped to organize nursing classes on behalf of the 'Darjeeling Mohila Samiti'. ${ }^{45}$ One article appeared in the Bangalakshmi (1927) is important to comprehend the psyche of the Bengali intellectuals towards the profession of nursing. The title of the article was 'Sebikar Kartobbya' with an English sub-title-Duties of a Nurse:

${ }^{40}$ Bangalakshmi, Vol. 5, No. 7, Chaitra 1336 B.S. (1929), p. 565.

${ }^{41}$ Bangalakshmi, Vol. 4, No. 1, Agrahayan 1335B.S. (1928), p. 861.

${ }^{42}$ Bangalakshmi, Vol. 7, No. 1, Falgun 1338 B.S. (1931), p. 300.

${ }^{43}$ Srimati Bina Dutta, 'Seba-Dharma', Bangalakshmi, Vol. 3, No. 10, Bhadra 1335 B.S. (1928), pp. 747-9.

${ }^{44}$ Srijukto Mohinimohon Bhattacharjee, 'Swami-Stree' (Husband and Wife), Bangalakshmi, Vol. 2, No. 10, Bhadra 1334 B.S. (1927), pp. 301-4. The story became very popular. It also highlighted the glorious role of the women organization in the emancipation of them.

${ }^{45}$ Prallahad Chandra Chakroborti, 'Mohila Samitir Karjyo', Bangalakshmi, Vol. 1, No. 4, Phalgun 1332 B.S. (1925), pp. $26-8$. 
information. In the hospitals one can find patient with such diseases in large number and there is very little chances of masscontagion. The well-trained nurses take the precautionary measures to tackle the contagious diseases in those hospitals.

Nursing is a well-established profession in Europe and America for long. Many schools and colleges are imparting nursing education and in the community of pupil, one can find, representatives from the respectable families also. There is no place for an amateur-training of nursing is a must. Even at the warfronts the trained nurses perform their duties with perfection. Miss Nightingale was the pioneer of modern-day nursing. The Red Cross Society works for the sick and destitute worldwide and nursing is a major part of their activity. A branch of this organization is already started working in India. Most of them are European nurses attached to various hospitals and residents of the rich Indian as private nurses.

Due to social taboos and proper education our women are mostly deprived from many things including nursing. But gradually some of them, from the lower castes, are interested to avail the nursing training. We hope with the spread of education and rationality, the female members of the high caste Hindus will also participate in the nursing profession. India is a poor country. Medical facility is a luxury to many. Thus recruiting trained nurses is difficult. Even in many Hindu households the entry of nurses, both Europeans and low-caste Hindus, is restricted. Thus again the female members of such families are solely responsible for nursing. Our intention is to enlighten them with few tips so that they can perform their duties well until our society is ready to accept nursing as a respectable profession..."46
This not to mean that the periodical Bangalakshmi, mainly used here to understand the perceptions of the Bengali community, is the only journal which portrays nursing profession in the Indian society. There must be many of them and further investigation will unearth such information no doubt.

\section{Towards Independence: Nursing AND Public Health-Care System}

Nursing arrangements, a very essential part of a hospital was, with few exceptions wholly unsatisfactory. In a circular to all Provincial Governments, the Government of India drew attention to the unsatisfactory condition of the nursing arrangements in the mofussil hospitals (1936). Trained nurses, pointed out the circular, were maintained only in few hospitals. Elsewhere, nursing was of the primitive type, being entrusted to female attendants, ward servants, compounders and relatives of the patients (Ray, 1998, p. 199). In the Bengal Legislative Assembly, several speakers drew attention to the lamentable state of nursing facilities in the hospitals of Bengal. ${ }^{47}$ In the hospitals of Calcutta also, the number of nurses was far from sufficient to cope with the growing demand for nursing. The famous daily Amrita Bazar Patrika noted that with the only exception of the Presidency General Hospital, nursing in all the other hospitals was unsatisfactory. ${ }^{48}$

Nursing was especially unsatisfactory in the Campbell Hospital, the largest pauper hospital in the Province. This was pointed out in the Bengal Legislative Assembly in 1939. ${ }^{49}$ Nursing at the Medical College Hospital was also inadequate and complaints were made to the Government on several occasions about the paucity of nursing

\footnotetext{
${ }^{46}$ Roy Bahadur Dr. Chunilal Basu, 'Sebikar Kartobbya' (Duties of a Nurse), Bangalakshmi, Vol. 2, No. 11, Aswin 1334 B.S. (1927), pp. 338-41.

${ }^{47}$ Reported in the Amrita Bazar Patrika, March 12, 1939, p. 7.

${ }^{48}$ This was partly due to the lack of sufficient number of trained nurses and partly to want of funds. 'Hospitals in Calcutta', Amrita Bazar Patrika, March 25, 1937, p. 7.

${ }^{49}$ See the Amrita Bazar Patrika, March 12, 1939, p. 7.
} 
personnel which hindered the smooth functioning of this coveted hospital. The Dacca Mitford Hospital seemed, in fact, to be the only hospital which had a properly organized nursing staff, but this was also inadequate for the size of the hospital. ${ }^{50}$

The State Medical Faculty of Bengal controlled the training of nurses and midwives and conducted the examinations in nursing and midwifery. It also granted certificates and maintained a register of trained nurses and midwives. Hospitals interested to send their candidates for training in nursing, at first applied to the State Medical Faculty which after satisfactory inspection granted their candidature for certificates in nursing. The length of the course for both senior and junior nursing certificates, approved by the State Medical Faculty, was three years. For midwifery certificates the duration was one year. The Presidency General Hospital and the Medical College Hospitals trained nurses for the senior certificates only. ${ }^{51}$

In the Presidency General Hospital and Medical College Hospitals, including the Eden and the Dufferin Hospital, the superior supervising nurses (matron) was usually recruited from the Europeans trained and experienced in England. The junior supervising staffs consisting of ward sisters and staff nurses in these hospitals were recruited from amongst the trained nurses who were alumni of these institutions. These were very important posts and constituted the backbone of nursing of any hospital. There were provisions for male nurses also. They were trained and employed in the Carmichael Medical College. In the Marwari Hospital nineteen out of the 22 nursing personnel were male nurses and there were three engaged in the Chittaranjan Hospital and twelve at the Ranaghat Mission Hospital. ${ }^{52}$ Very few know that Dr. Bidhan Chandra Roy, the second Chief Minister of West Bengal, used to work as a malenurse during his studentship at the Calcutta Medical College. To tackle the stringent financial crisis, the teachers of the Medical College Hospital kindly send Bidhan Chandra to the houses of the wealthy residents of Calcutta in his leisure time. Thus the poor student found some support to continue his medical education. ${ }^{53}$

We may here refer to the Report of the Nursing Committee (1932) appointed by the Government of Bengal which was strongly of the opinion that-

"...good nursing plays a very important
part in scientific medicine (including
surgery and midwifery) and that the
highest results cannot be obtained even
by the best physicians and surgeons
without the co-operating agency of high
class nursing adequate in quantity and
quality." 54

This opinion was also corroborated by many Indian and European surgeons and physicians of high reputation. The Committee was

\footnotetext{
${ }^{50}$ Major E J Montgomary, the Civil Surgeon of Dacca and Superintendent of the Mitford Hospital, while addressing a meeting of the Dacca Rotary Club on 'Nursing in Bengal' in 1938, said that almost two lacs of people were treated annually in the wards of the hospitals in Bengal and yet it is no exaggeration to say that in very few of them sufficient nursing arrangements existed, and even where it existed it was inadequate for the needs of the institution, while many hospitals possessed no nursing staff at all. Even in many places where nursing was available, there was no provision for night nursing staff, and untrained attendants were employed. Montgomary referred to the Dacca Hospital where there was an average of 300 patients with a staff of two nursing sisters, five staff nurses and twenty-one probationers and it was found impossible to provide any nursing staff during the night. Quoted in Ray, op.cit, p. 200.

${ }^{51}$ Government of Bengal, Local Self-Government Department, Medical Branch, File No. N—5, Progs. No. 94, February 1936, WBSA.

${ }^{52}$ Ibid.

${ }^{53}$ Young Bidhan used to get Rs. 8 for twelve hours duty. Sankar, 2014, p. 1.

${ }^{54}$ Government of Bengal, Local Self-Government Department, Medical Branch, File No. N_5, Progs. No. 94, February 1936, WBSA.
} 
also of opinion that the aims of modern scientific medicine in Calcutta and throughout Bengal were largely frustrated by the lack of inadequate nursing. The Committee felt that amongst the rank and file of medical profession in Bengal, there was a lack of appreciation of the above-mentioned facts and those doctors in Bengal did not, throughout their training, appreciate the essential part played by adequate and skillful nursing in the treatment and recovery of patients. ${ }^{55}$

From an examination of the number of beds of various hospitals, the Committee felt that there was a very great diversity in these hospitals with regard to provisions for nursing. Among the better category may be mentioned Chittaranjan Seva Sadan, Eden Hospital, Dufferin Hospital, and Presidency General Hospital. In none of the other hospitals, according to the Committee, nursing was really adequate. In the Medical College Hospitals (excluding the Eden Hospital) there was a distinct shortage of nurses. ${ }^{56}$ Actually, however, the number of beds in occupation was many more than sanctioned, so that the ratio was really much higher than shown. It is also a fact that at night, besides the night-sister, there were no fully trained nurses on duty even in the operation theatres. The Committee endeavoured to arrive at some definite numerical standard of numbering, both for supervising and for working staff: "Both supervising and working nursing staffs are important and each may fill definite places in a good nursing scheme. We consider that in a teaching hospital, the overall ration of beds per nurse should not exceed 3.5 beds to 1 nurse." 57

The Committee paid particular attention to the question of the participation of the Bengali young women in the profession of nursing. Nursing in England owed its inception to the example of Florence Nightingale who lifted it from the menial and degrading occupation to a profession of highest qualities-demanding knowledge, devotion, self-sacrifice and hard work. But the situation was entirely different in Bengal. It was largely looked down upon as an occupation of an inferior nature. So far as Indian women were concerned most of them belonged to the Christians community and widows and few needy women driven by absolute necessity to seek a means of livelihood. The Committee highlighted the challenges-

"(1) Nursing is considered derogatory by
high caste Hindus; (2) There is an
aversion to nurse male patients; (3) The
upbringing hitherto of good class Indian
girls has been of a very sheltered nature
and to leave this and mix with the world
and live an independent life is not yet
considered to be correct; (4) The
opportunities for training of such young
women have not hitherto been many and
the accommodation and difficulties of

\begin{tabular}{lcc}
\hline${ }^{55}$ Ibid. & & \\
\multicolumn{2}{l}{ Number of beds and the ratio of beds per nurse in some of the important hospitals of Calcutta- } \\
\hline Name of the Hospitals & Total Number of Beds & Ratio of Beds per Nurse \\
\hline Chittaranjan Seva Sadan & 125 & 2.23 \\
Eden Hospital & 106 & 2.52 \\
Dufferin Hospital & 148 & 2.96 \\
Presidency General Hospital & 235 & 3.1 \\
Medical College Hospitals (excluding Eden) & 583 & 5.88 \\
Carmichael Medical College & 330 & 7.00 \\
Campbell Hospital & 717 & 27.98 \\
Mitford Hospital, Dacca & 260 & 9.28
\end{tabular}

Report of the Nursing Committee, Appendix II, Government of Bengal, Local Self-Government Department, Medical Branch, File No. N-5, Progs. No. 94, February 1936, WBSA.

${ }^{57}$ Ibid. 
food, etc, have, perhaps, not been such as to attract this class; (5) There is still a lack of appreciation in Indian families of the necessity of nursing for a sick person, and this outlook as has been explained above is still very prevalent even in the average doctor trained in India. Any member of the family is considered capable of doing what is necessary for the patient." 58

In tune with this report (1932), the contemporary literature also blames widespread stigmatization and the strength of the caste system for the chronic underdeveloped state of nursing in India. As Madelaine Healey recently argues, attempts to develop modern nursing in India certainly suffered from the feeling in polite Indian society that the work of nurses in hospitals was very close to the work of servant castes considered untouchables. This, of course, had also been an important aspect of the development of nursing in the West. But in the Indian context, however, the stigmatization of nursing as servant work took on added force under the caste system (Healey, 2011, pp. 55-75).

In Bengal, the understanding of nursing work as low-status servants' work meant that until the 1940s, the majority of candidates for nursing were widows, orphans or destitute converts to Christianity from lower castes, most of whom had no other option. Ethel Bleakley, a doctor from Manchester working at a mission hospital in Ratnapur, examined the lives of Indian nurses working in her hospital during the 1930s and 1940s. She recorded, for example, the work of Shoila, a Muslim widow who converted and took nursing training. Shubala, a Christian from Calcutta who had made a socially well-regarded marriage, was deserted by her husband for a wealthier woman and brought to the mission by penurious relatives keen to ensure her safety. She proved a highly capable nurse and was put in charge of a new maternity hospital opened by the mission (Bleakley, 1949, pp. 60-63). In spite of the difficulties, the Nursing Committee recommended: "... every effort should be made to encourage educated young women of the better classes in Bengal to enter the nursing profession and to undergo training for the senior nursing certificate." ${ }^{59}$ For example, one Nalini Bala Choudhury obtained nursing training from her husband Dr. Mahim Chandra Choudhury who was himself a medical practitioner. Nalini Bala specialized in obstetric nursing and became famous in their locality for her skill. ${ }^{60}$ Properly trained nurses were the crying need of most of the hospitals but as was pointed out by a member of the Bengal Assembly in 1945, the successive Governments were far too apathetic and lethargic in tackling the problem of nursing (Ray, op. cit., p. 201).

Trained hospital nursing as a medical modernity had by the early twentieth century become so widely accepted that both the foreign Government and their Indian subject offered rhetorical support to the betterment of nursing. Substantive support, however, was minimal, at least until the 1940s. The British Government accepted a situation in which the majority of Indian state-run hospitals functioned with either a minimal nursing staff or no nursing staff at all. The Bengali intellectuals raised their voice but without any effect.

Subsequent developments were influenced by the report of the Bhore Committee (1946). It was set up by the Government of India under the

\footnotetext{
${ }^{58}$ There was absolutely no guarantee that a well-educated Indian girl coming from a good family would choose nursing as her desired profession. Such young educated women naturally turned to either teaching or profession of medicine. Even the latter did attract very few educated Bengali women. Ibid.

${ }^{59}$ Government of Bengal, Local Self-Government Department, Medical Branch, File No. N—5, Progs. No. 94, February 1936, WBSA.

${ }^{60}$ Unfortunately we don’t have sufficient information about Nalini Bala. See Shyamali Gupta, 2013, p. 174.
} 
chairmanship of Sir Joseph Bhore. Dealing with education in general and nursing in particular, the Bhore Committee made numerous useful observations regarding the state of nursing education and profession in India. In this country the number of nurses was woefully small. An extract from the report:

"The nurses whose names are on the
various registers differ greatly in their
professional ability and their educational
background. There are at present
approximately 190 schools where training
recognized by the Nursing Council is
undertaken, but these training schools are
far from satisfying even the minimum
requirements of modern training
institutions. In most of them students are
employed as un-paid nurses, working
long hours with no adequate time for
study. In that way in almost every hospital
in India, the education of the nurse is
sacrificed to the urgent demand of nursing
service. Furthermore, in no hospital there
is staff adequate either in numbers or
experience to provide the necessary
instruction and the supervision of
training."

The Committee was in favour of shortterm policy regarding nursing, as the longterm goals were so intimately connected with the post-war development plan, that it must await their collateral development. To their opinion, the spread of education up to at least the high school standard would eventually attract large numbers to the profession. The Committee recommended the establishment of a sufficient number of preliminary training schools to instill into students (prospective nurses and midwives) a preventive approach to health problems from the very beginning. The nursing course can be made interesting, they thought, only if it is correlated with existing educational backgrounds and linked to community and home conditions. To the opinion of the Bhor Committee, along with the junior and senior grades, a university degree course (post-graduate training) in nursing was urgently required. ${ }^{62}$

First it was proposed that, the School of Nursing Administration at Delhi, originally established in 1943, should be transformed into a College of Nursing. It was hoped that eventually the three provinces of Madras, Bombay and Bengal and other larger provinces of India would develop their own nursing colleges. Advanced courses for trained nurses in hospital administration, sister-tutor courses, courses for public health supervisors and others should be instituted at the earliest - the Committee further recommended.

\section{Conclusion}

Nursing in India has suffered from persistent underdevelopment and widespread stigmatization. This was further deteriorated with the strength of the caste system. In upper-caste and middle-class society, the care of the sick was seen as an important dimension of women's work in a controlled private sphere. Modern nursing posed a significant challenge to these local practices. The displacement of such key elements of women's domestic work into the public environment of the hospital created considerable discomfort and moral suspicion about those women willing to provide this kind of care to strangers. Thus nursing was restricted to the lowcaste Hindus, converted Christians and the AngloIndians. The position of nursing in the colonial politics of health is a complex phenomenon. The nurses were not meaningfully viewed by the state either as tools of empire or as heroines; rather, they and their projects for improvement were

\footnotetext{
${ }^{61}$ Report of the Health Survey and Development Committee (Bhore Committee), 1946, p. 387.

62 "Degrees in nursing are given by certain Canadian and American Universities and London University awards a Diploma in this subject. We consider it essential that such a degree course in nursing should be instituted as early as possible in India in order to provide leaders for the nursing profession from among the more highly educated and cultured ladies.” Ibid, p. 388.
} 
largely ignored. The Government officials were content to take refuge in notions of the unchallenged cultural alienation of the Indian population. At independence (1947), the nursing profession was stunningly underdeveloped. In part, this reflected a generally very low level of provision for public health care in India, especially for the Indians. Even in the context of a generally inadequate health system, however, nursing was particularly neglected. The state when wished to build the kind of nursing profession that was essential to the institution of the modern hospital, they faced a considerable challenge within the Indian society. There were very few takers. But by the 1920s a large section of the Bengali intellectuals raised their apprehension for the deplorable state of nursing along with the physicians. This was evident in the contemporary vernacular press. A number of initiatives were taken by them that set aside questions of status and stigma related to nursing and tried instead to rationalize and organize around the present needs of hospitals. But this was not enough to remove the age-old superstitions and convince the reluctant Bengali middle class. Thus the strange condition in the hospitals persisted throughout the first half of the twentieth century with very limited Indian participation in the nursing profession. Angela Bolton, an Army Nurse while posted in Combined Military Hospital, Asansol (1942-45), wrote-

\footnotetext{
"When the time for my three weeks' night duty came up I had to take leave of the magnificent fridge and cross over to the Indian block. The Indian wards were a revelation to me. I came face to face with strange diseases I had never heard of. Infestation with guinea worm, the oldest known human parasite, which the orderlies twisted round a small stock as it issued from the muscle of the leg, was quite common; elephantiasis, caused by another parasitic worm carried by mosquitoes, was rarer but devastating in
}

its later stages. Night duty on the Indian wards was made more hazardous by intruders from the animal kingdom..." 63

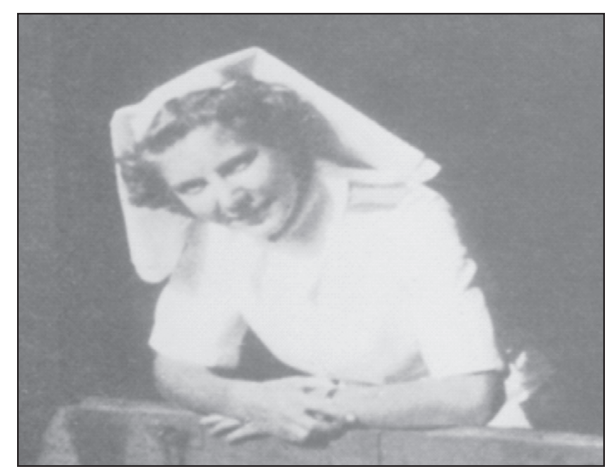

Angela Bolton: The members of Queen Alexandra's Imperial Military Nursing Service played a vital role tending sick and wounded soldiers in every theatre of the Second World War. Bolton joined the QAIMNS in 1941 as a reserve sister. Early in 1942 she was posted to India. For three and half years she worked in military hospitals and river steamers in Bengal and Assam.

\section{ACKNOWLedGements}

I owe a profound debt of gratitude to Prof. Srilata Chatterjee, my supervisor, for her tireless support and encouragement and her invaluable scholarly suggestions at all stages of my work. I would also like to thank Prof. Sujata Mukherjee who read my M Phil Dissertation, offered valuable comments. I am especially grateful to Prof. Deepak Kumar with whom I discussed at length various aspects of my research and his advice helped me to formulate my arguments well. I also thank Prof. Biswamoy Pati, Prof. Bipasha Raha, Dr. Neelam Kumar, Dr. Jayanta Bhattacharya and Dr. Debjani Das for their suggestions and encouragement. My discussions with Dr. Shilpi Rajpal, my friend, helped me in clarifying many of my ideas.

\section{BiBLIOGRAPHY}

\section{Primary Sources}

1. West Bengal State Archives (WBSA), Kolkata: Proceedings of the Municipal Department, Medical

\footnotetext{
${ }^{63}$ Angela Bolton, 1986, pp. 90-1.
} 
Branch and Proceedings of the Local SelfGovernment, Medical Branch

2. National Archives of India (NAI), New Delhi: Proceedings of the Home Department, Medical Branch

3. Government Reports: Report of the Health Survey and Development Committee (Bhore Committee), Vol. II, Ministry of Health, Government of India, New Delhi, 1946.

4. Contemporary Periodicals in Bengali and English: Bangalaksmi, The Amrita Bazar Patrika

\section{Contemporary Publications}

Dock, Lavinia. A History of Nursing, The Knickerbocker Press, New York and London, 1912.

Mill, C. R. 'Some Advantages of Joining the TNAI', The Nursing Journal of India, Vol. I, No. 1, February 1910, pp. 7-13.

\section{Secondary Sources}

Bhattacharya, Jayanta. 'The genesis of hospital medicine in India: The Calcutta Medical College (CMC) and the emergence of a new medical epistemology', The Indian Economic and Social History Review, Vol. 51, No. 2, 2014, pp. 231-64.

Bleakley, Ethel. Meet the Indian Nurse, Zenith Press, London, 1949.

Bolton, Angela. The Maturing Sun: An Army Nurse in India, 1942-45, Imperial War Museum, London, 1986.

Bose, Pradip Kumar (ed.). Health and Society in Bengal: A Selection from the Late $19^{\text {th }}$ Century Bengali Periodicals, Sage, New Delhi, 2006.

Bridges, Daisy. A History of the ICN 1899-1964: The First Sixty-five Years, J. B. Lippincott Co, Philadelphia, 1967.

Brush, Barbara L. and Meryn Stuart. 'Unity Amidst Difference: The ICN Project and Writing International Nursing History', Nursing History Review, Vol. 2, 1994, pp. 191-203.

Development of Nursing Education in India, National Institute of Health Administration \& Education; Institute of Applied Manpower Research, New Delhi, 1966.

Fitzgerald, Rosemary. 'Making and Moulding the Nursing of the Indian Empire', in Avril A. Powell and Siobhan Lambert-Hurley (eds.), Rhetoric and Reality: Gender and the Colonial Experience in South Asia, Oxford University Press, New Delhi, 2006, pp. 183-222.

Gayathri, Ch. Radha. Female Health Care in Colonial North India: A Study of Medical and Educational Interventions, $\mathrm{PhD}$ Thesis, Jawaharlal Nehru University, July 2007.

Gourlay, Jharna. Florence Nightingale and the Health of the Raj, Ashgate, Aldershot and Burlington, VT, 2003.

Gupta, Shyamali, Banga Mohila Choritabidhan, Sahityalok, Second Edition, Kolkata, 2013.

Harrison, Mark, et al (eds.), From Western Medicine to Global Medicine: The Hospital Beyond the West, Orient Blackswan, New Delhi, 2009.

Hasan, Narin. Diagnosing Empire: Women, Medical Knowledge and Colonial Mobility, Ashgate, Aldershot and Burlington, VT, 2011.

Healey, Madelaine. 'Regarded, paid and housed as menials: nursing in colonial India, 1900-1948', South Asian History and Culture, Vol. 2, No. 1, January 2011, pp. 55-75.

Healey, Madelaine. Indian Sisters: A History of Nursing and the State, 1907-2007, Routledge, New Delhi, 2013.

Macleod, Roy (ed.). Disease, Medicine and Empire: Perspectives on Western Medicine and the Experience of European Expansion, Routledge, London and New York, 1988.

Pal, Prasantakumar. Rabijibani, Vol. 5, Ananda, Kolkata, 1990.

Ray, Kabita. History of Public Health: Colonial Bengal 1921-1947, K. P. Bagchi \& Co, Calcutta, 1998.

Rosenberg, Charles. The Care of Strangers: The Rise of America's Hospital System, The John Hopkins University Press, Baltimore and London, 1987.

Sankar. 'Dak-nam Bhajon, Bhalo-nam Bidhan', in 'Saturday Supplement', Ananda Bazar Patrika, June 28, 2014, p. 1.

Sarkar, Suvobrata. The Quest for Technical Knowledge: Bengal in the Nineteenth Century, Manohar, New Delhi, 2012.

Sehrawat, Samiksha. Colonial Medical Care in North India: Gender, State and Society c. 1840-1920, Oxford University Press, New Delhi, 2013.

Tomes, Nancy T., and Geertje Boschma. 'Above All Other Things-Unity', in Barbara L. Brush et al (eds.), Nurses of All Nations: A History of the International Council of Nurses, 1899-1999, Lippincott, Philadelphia and New York, 1999, pp. 1-38. 